\title{
Ameliorative Effect of Proline and Ascorbic Acid on Seed Germination and Vigour Parameters of Tomato (Solanum lycopersicum L.) Under Salt Stress
}

\author{
H. Kaur* and N. Gupta
}

Department of Botany, Punjab Agricultural University, Ludhiana-141004, Punjab, India

*Corresponding author

\section{A B S T R A C T}

\begin{tabular}{|l|}
\hline K e y w o r d s \\
$\begin{array}{l}\text { Tomato, Salt stress, } \\
\text { Seed treatments, } \\
\text { Proline, Ascorbic acid, } \\
\text { Germination rate }\end{array}$ \\
\hline Article Info \\
\hline $\begin{array}{l}\text { Accepted: } \\
\text { 26 September } 2017 \\
\text { Available Online: } \\
\text { 10 November } 2017\end{array}$ \\
\hline
\end{tabular}

\section{rds}

Proline, Ascorbic acid,

Germination rate

\section{Introduction}

Tomato (Solanum lycopersicum L.) is a major crop from family Solanaceae and is rich in minerals, vitamins, essential amino acids, sugars and dietary fibres that contribute to healthy and balanced diet (Palop et al., 2010).

Plants are exposed to several abiotic stresses during its growth and development. Saltstress is one of the most prime hindrances in salt affected area of the world for crop production. At present, nearly $6.5 \%$ of whole area of the world and around $20 \%$ of the cultured land is affected by salinity (Billah $e t$ al., 2017). High levels of salt in soil causes imbalance in osmotic potential, ionic equilibrium and nutrient uptake (Nawaz et al., 2010).
Salinity stress reduce plant yield by affecting physiology as well as biochemistry of plant (Hemalatha et al., 2017). Excess amount of salt adversely affects plant growth and development and decreases yield and crop productivity (Manaa et al., 2011). In tomato, salinity affects adversely different growth stages (Zhang et al., 2017) and seed germination (Singh et al., 2012). Salinity reduces fresh weight and dry weight of seedlings (Mansour and Ali 2017).

Proline is proteinogenic amino acid which has a unique rigidity by conformation and is necessary for primary metabolism. Proline accumulates in response to drought and 
salinity (Nahar et al., 2016). It has been reported that proline accumulation provides resistance to salinity stress (Nazarbeygi et al., 2011). Pre-sowing application of proline enhances germination parameters under abiotic stress conditions in radish (Shruti et al., 2015). Positive effects of seed treatment were reported for Tomato (Shalata and Neumann 2001).

Ascorbic acid (AsA) is one of the most abundant antioxidants found in plants. It is water-soluble and anti-oxidant molecule that acts as a primary substrate for detoxification of hydrogen peroxide (Akram et al., 2017). Ascorbic acid decreases adverse effects of salt stress on plant growth. Ascorbic acid play major role in stress by regulating complex sequence of biochemical reactions, induction of stress responsive protein synthesis, and the producing of various chemical defense compounds (Khan et al., 2011).

Seed treatment of ascorbic acid (vitamin C) in tomato increase resistance to salinity probably by decreasing the synthesis of active oxygen species (Sayed et al., 2016). Ascorbic acid is reported to improve the salinity tolerance in potato (Sajid and Aftab. 2009). Positive effects of ascorbic acid on growth are reported in wheat (Rafique et al., 2011).

\section{Materials and Methods}

Seeds of tomato genotypes (PVB-4 and Roma) were surface sterilized by $0.1 \%$ solution of mercuric chloride followed by thorough washing by distilled water. Salinity stress was imposed by moistening the germination papers in petri dishes with solutions of different salinity concentrations of $\mathrm{NaCl}$ (Control, 25mM, 50mM, $75 \mathrm{mM}$ and $100 \mathrm{mM} \mathrm{NaCl})$. The petri dishes were placed in an incubator at $25^{\circ} \mathrm{C}$ and $60 \pm 15 \%$ relative humidity for 14 days to record the effect of salinity on germination parameters. Three salinity levels were selected. The seeds were pre-treated for 2 hrs with different concentrations of proline $(5 \mathrm{mM}$ amd $10 \mathrm{mM})$ and ascorbic acid ( $1 \mathrm{mM}$ and $4 \mathrm{mM})$. These treated seeds were subjected to salinity stress.

After fourteenth day, the seedlings were evaluated and the normal seedlings were counted and expressed in percentage (ISTA, 2011). At the time of germination count, five normal seedlings were selected at random from each replication and used for measuring seedling length. The values were expressed in centimeter. For calculating seedling dry weight, seedlings were dried in oven at $110^{\circ} \mathrm{C}$ for 17 hours and expressed in milligrams. Vigour index of seeds were calculated as suggested by Abdul Baki's Anderson (1973).

Vigour Index I = Germination (\%) x Seedling length $(\mathrm{cm})$

Vigour Index II = Germination (\%) $\mathrm{x}$ Seedling dry weight (g)

\section{Statistical analysis}

The statistical analysis was carried out by using SPSS-16.

\section{Results and Discussion}

Seed germination is an important stage that determines the crop production. Percent germination declines with increasing salinity levels. In present study, both the concentrations of proline and ascorbic acid increased the percent germination over control in PVB-4 and Roma at all salinity levels. But the affect of Proline $10 \mathrm{mM}$ and ascorbic acid $4 \mathrm{mM}$ was more as compared to proline $5 \mathrm{mM}$ and ascorbic acid $1 \mathrm{mM}$ respectively as showed in figure(1). Germination percentage declined with the increase in salinity levels (Hemalatha et al., 2017). Proline has an important role in increasing germination and it also increases resistance to various stresses (Kaur et al., 
2015). According to Talat (2013) foliar spray of proline promotes the salt tolerance and germination percentage, growth and chlorophyll contents in wheat. Pretreatment with ascorbic acid enhanced the germination in Silybum marianum (Ekmekci and Karaman 2012).

Similarly, it has been studied that seedling length was maximum at lower salinity level $(25 \mathrm{mM})$ and gradually decreased with higher salinity level in both the genotypes. It has been observed that pretreatment of proline as well as ascorbic acid enhanced seedling length at all salinity levels. As depicted in figure (2), the affect of ascorbic acid $4 \mathrm{mM}$ was maximum at all salinity levels in PVB-4 and Roma. Tomatoes inhabiting in saline environments lead to restricted root growth (Zhang et al., 2016). Farooq et al., (2011) reported that presoaking of seeds with different salts improved the seedling emergence, shoot and root length.

Fig.1 Influence of seed treatments on percent germination of tomato (Solanum lycopersicum L.) under salt stress (a) Punjab Varkha Bahar-4 (b) Roma

(a)

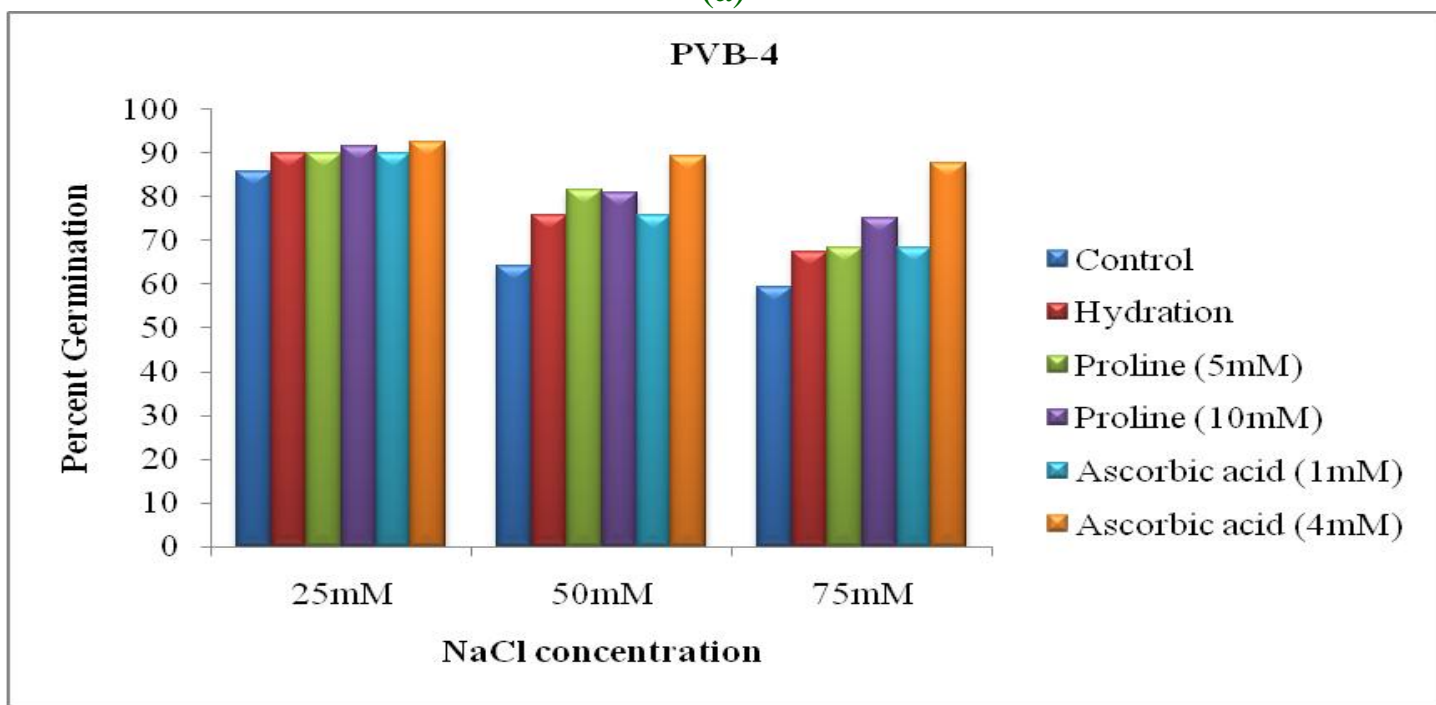

(b)

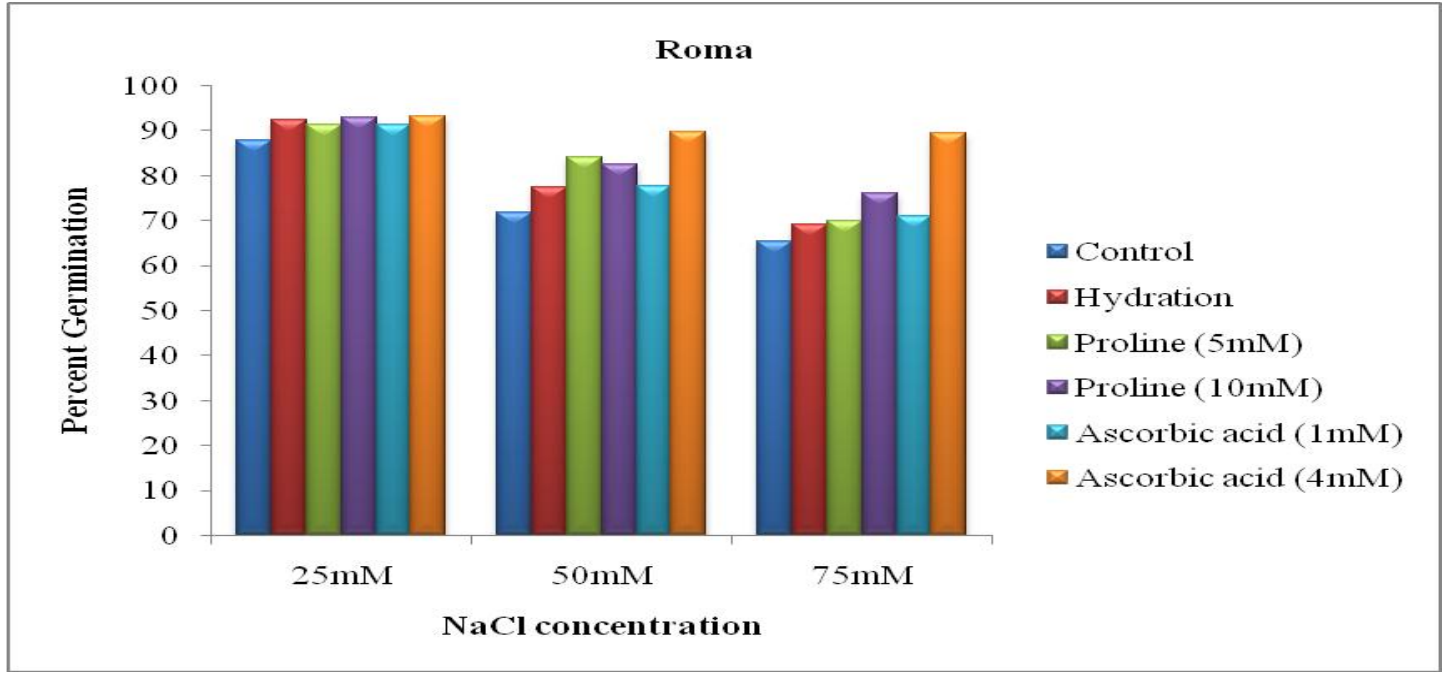


Fig.2 Influence of seed treatments on seedling length $(\mathrm{cm})$ of tomato (Solanum lycopersicum L.) under salt stress (a) PVB-4 (b) Roma

(a)

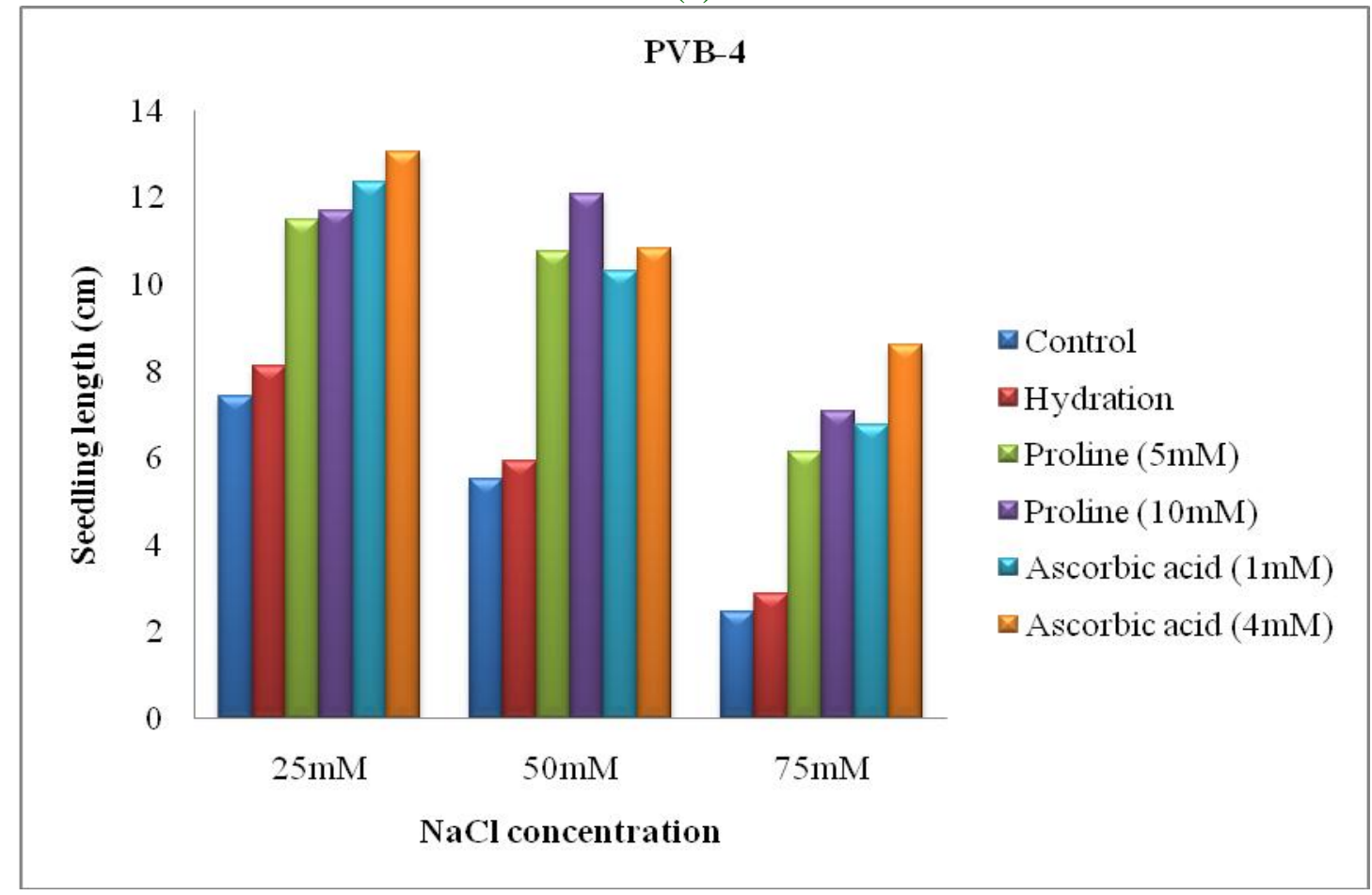

(b)

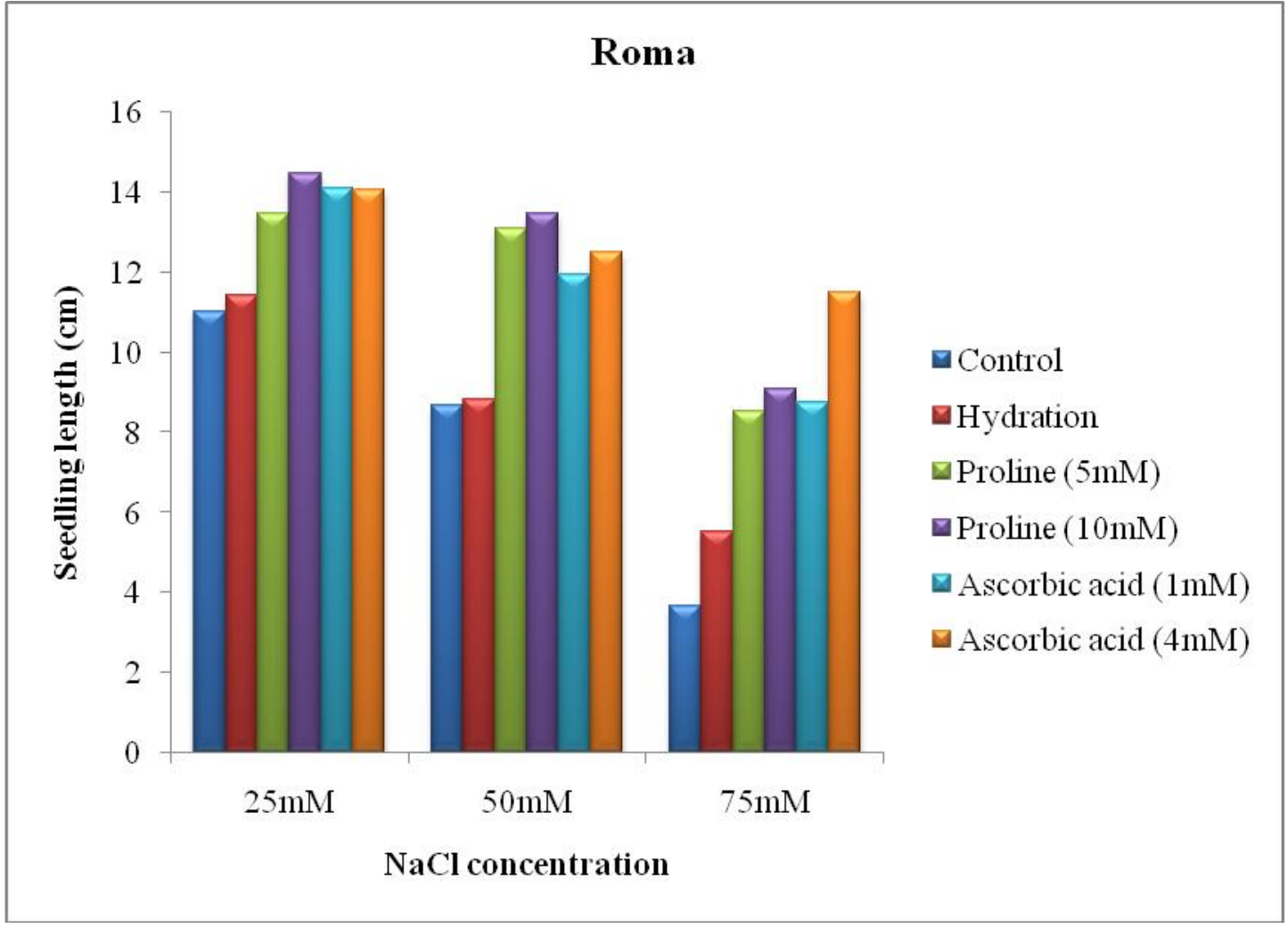


Fig.3 Influence of seed treatments on fresh weight $(\mathrm{mg})$ of tomato (Solanum lycopersicum L.) under salt stress (a) PVB-4 (b) Roma

(a)

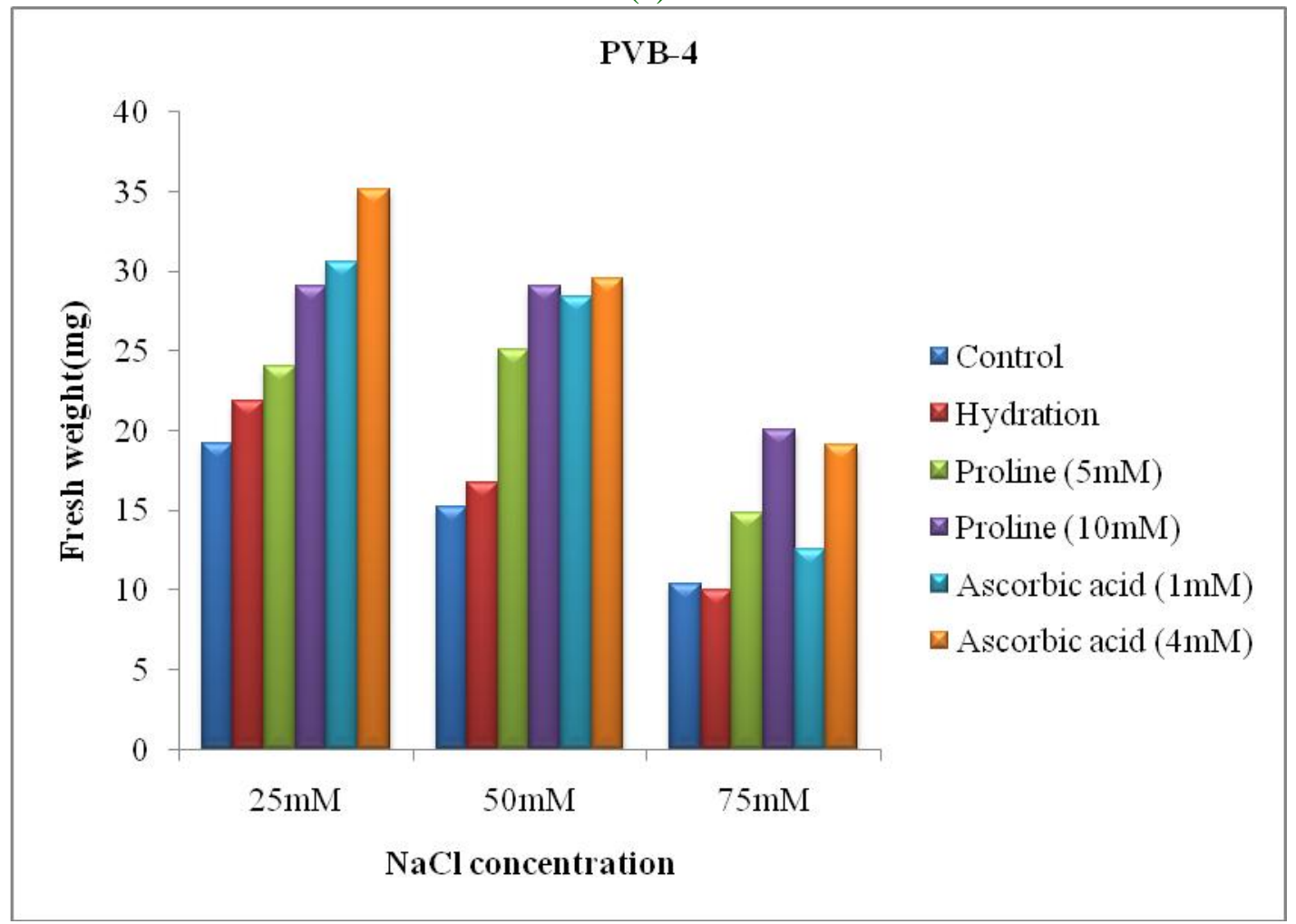

(b)

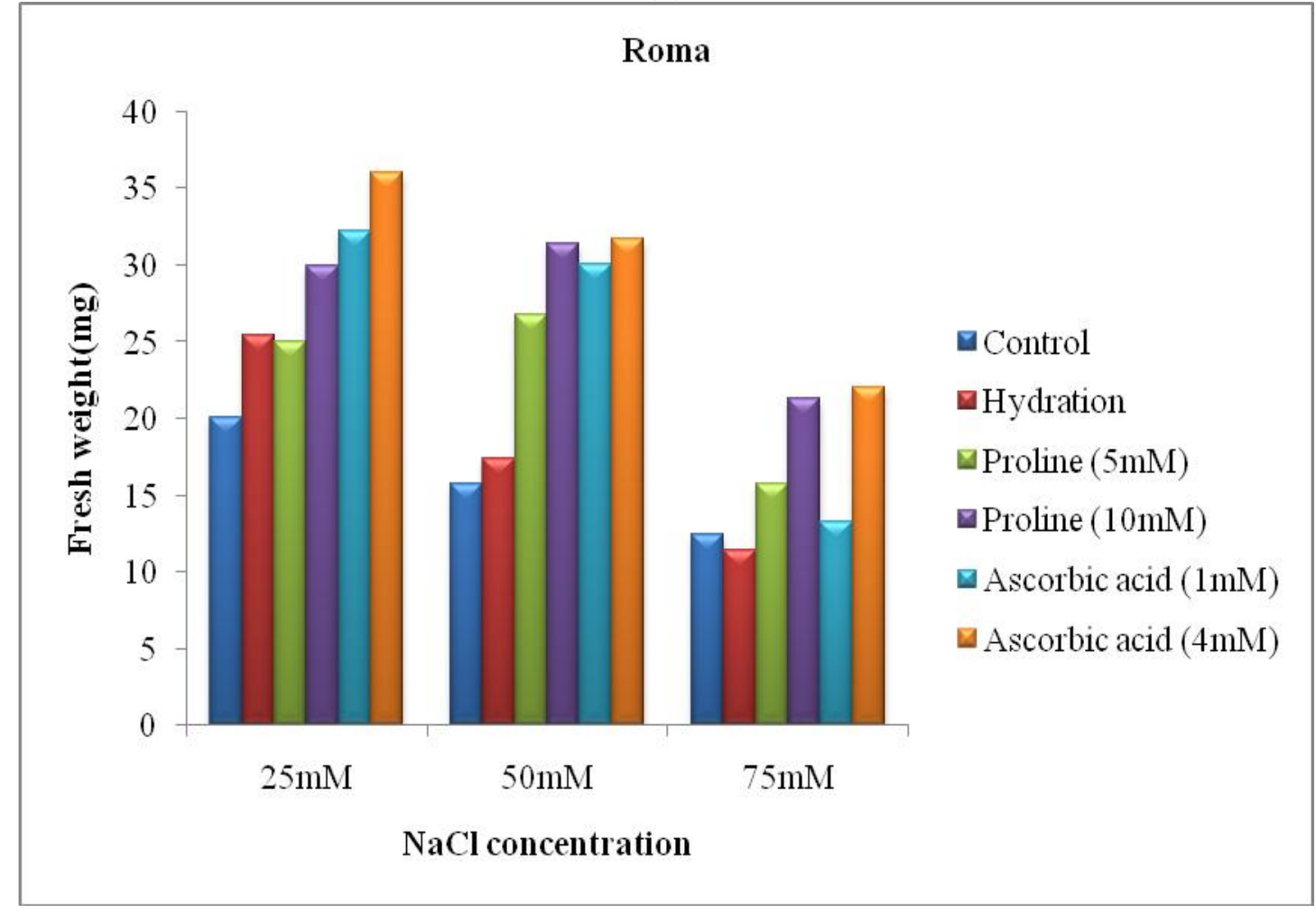


Fig.4 Influence of seed treatments on dry weight (mg) of tomato (Solanum lycopersicum L.) under salt stress (a) PVB-4 (b) Roma

(a)

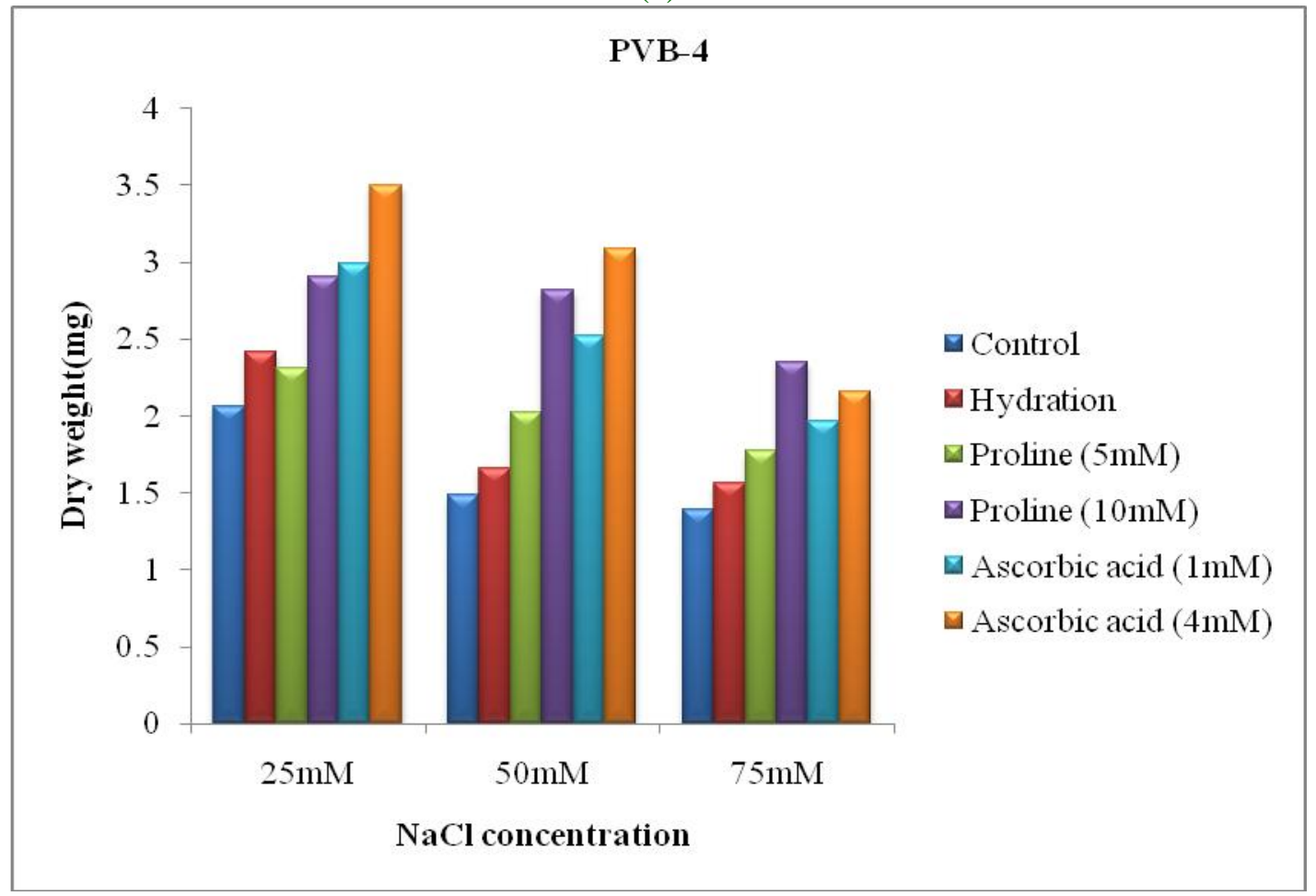

(b)

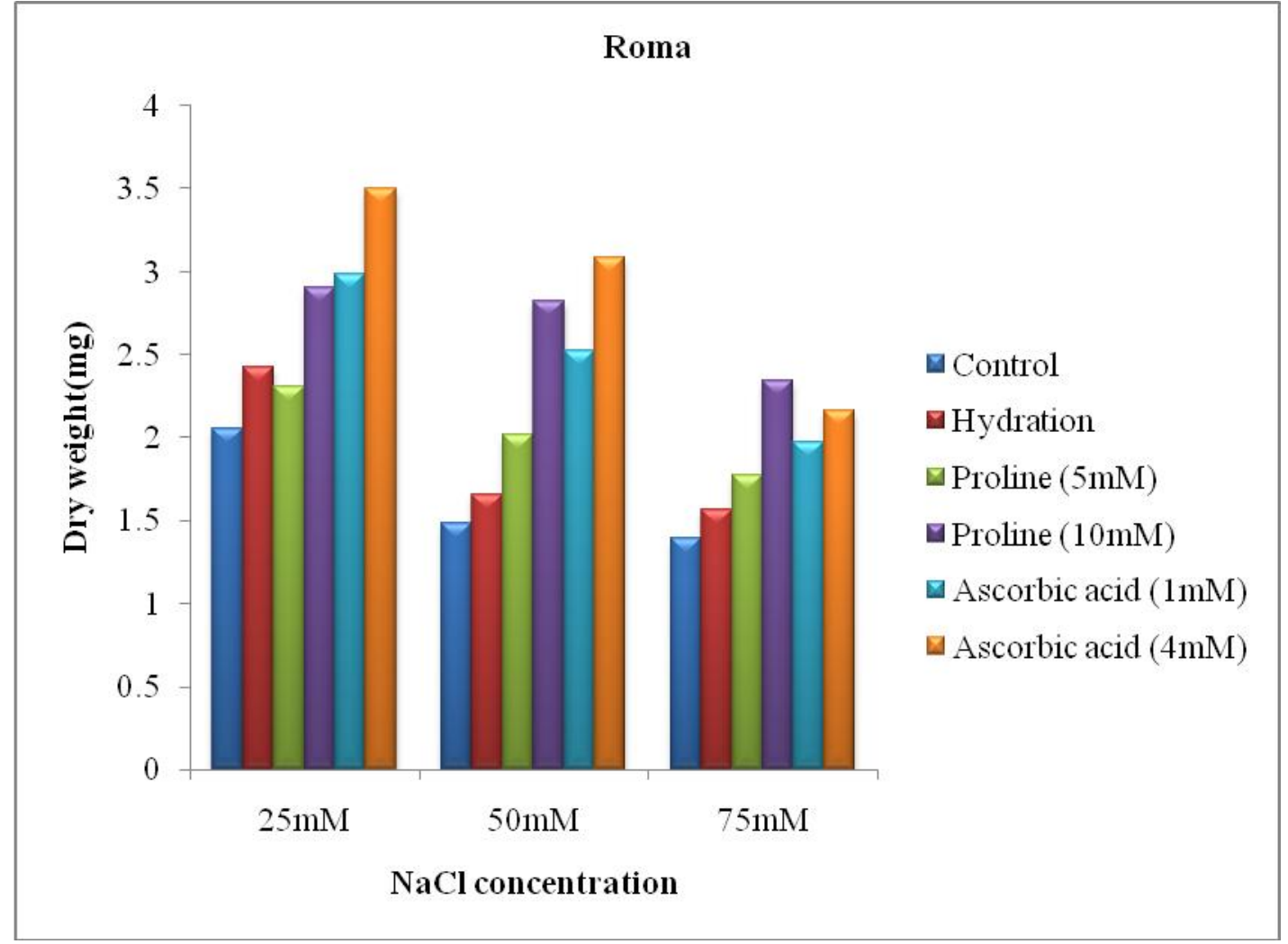


Fig.5 Influence of seed treatments on seed vigour I of tomato (Solanum lycopersicum L.) under salt stress (a) PVB-4 (b) Roma

(a)

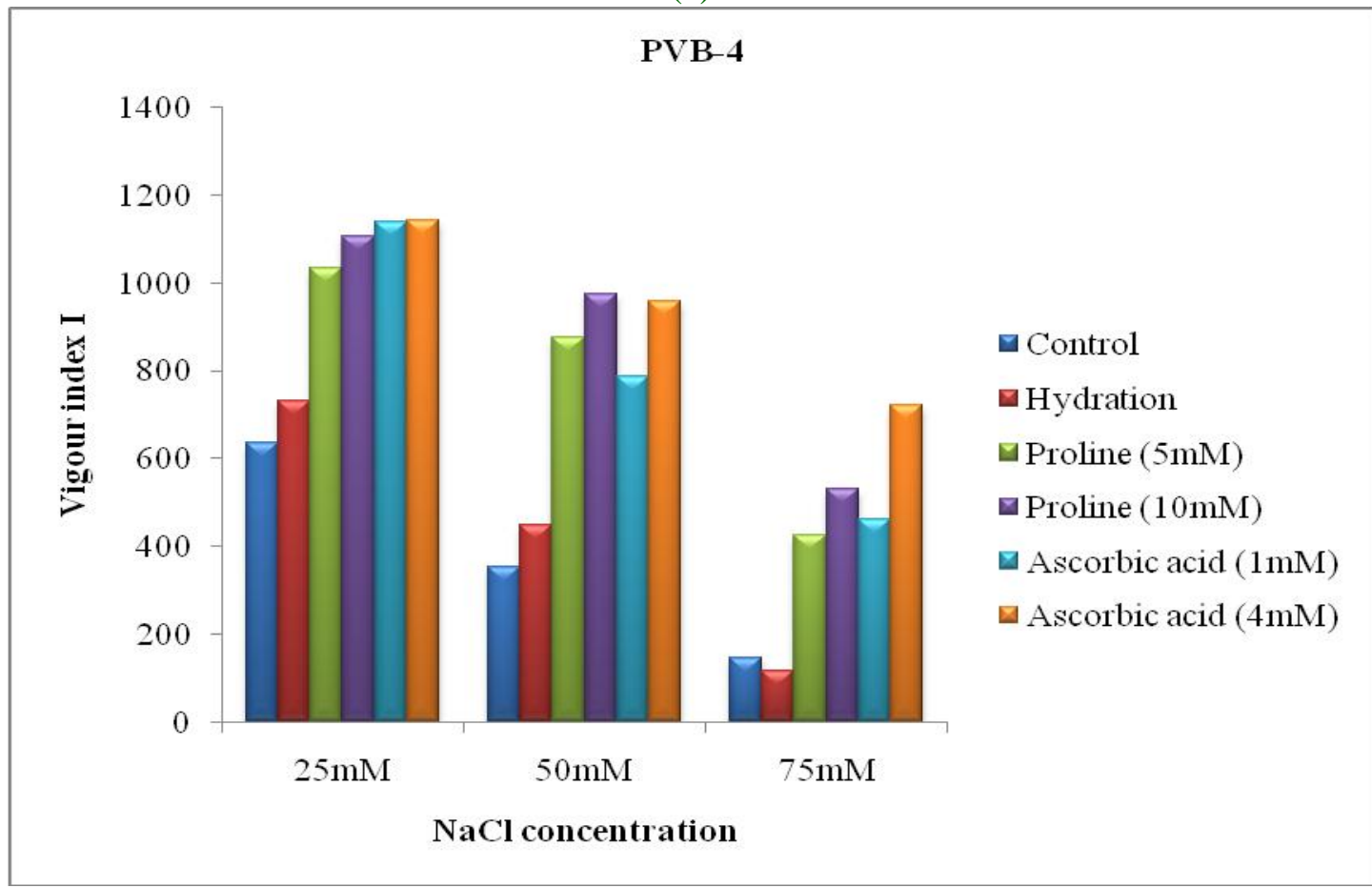

(b)

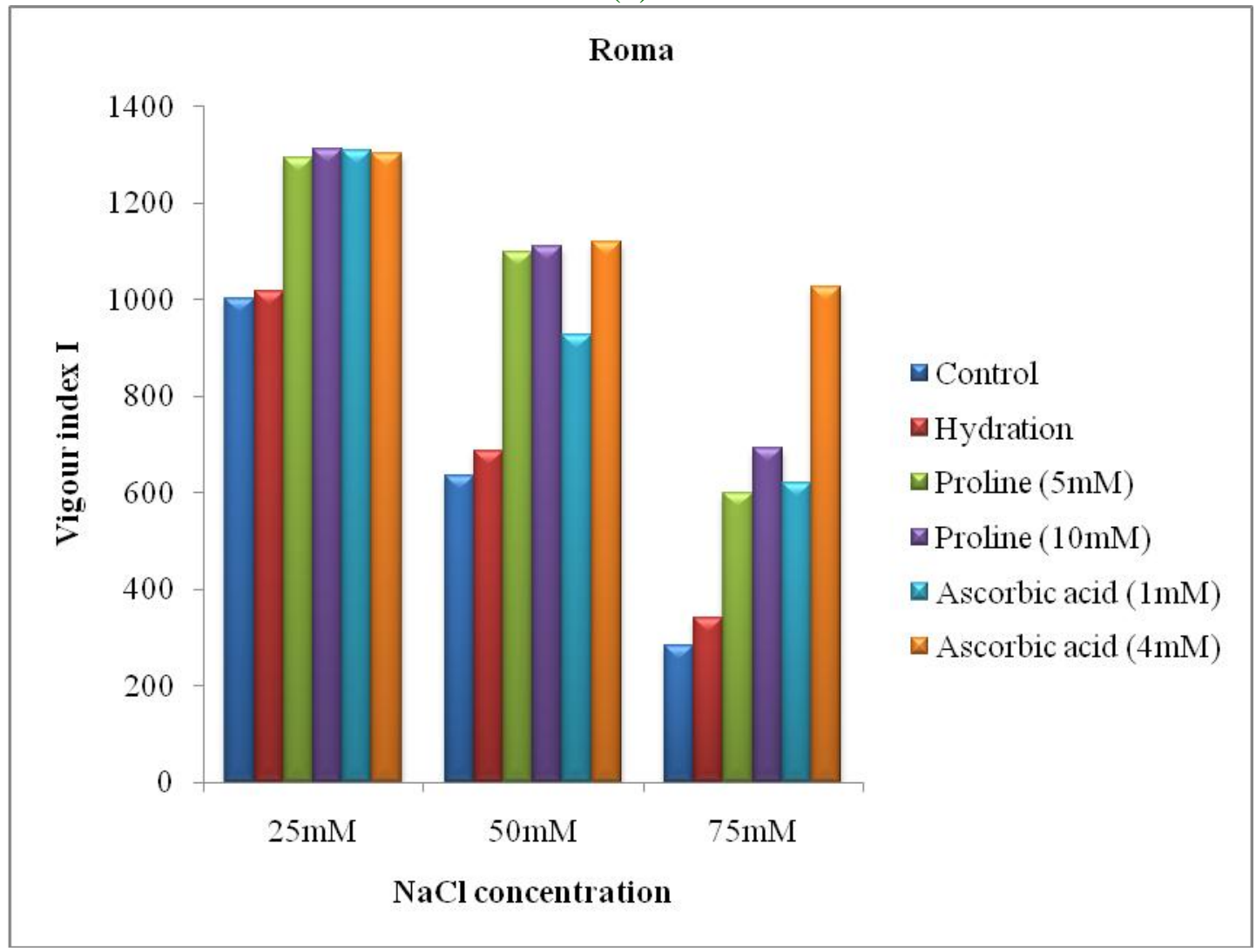


Fig.6 Influence of seed treatments on seed vigour II of tomato (Solanum lycopersicum L.) under salt stress (a) PVB-4 (b) Roma

(a)

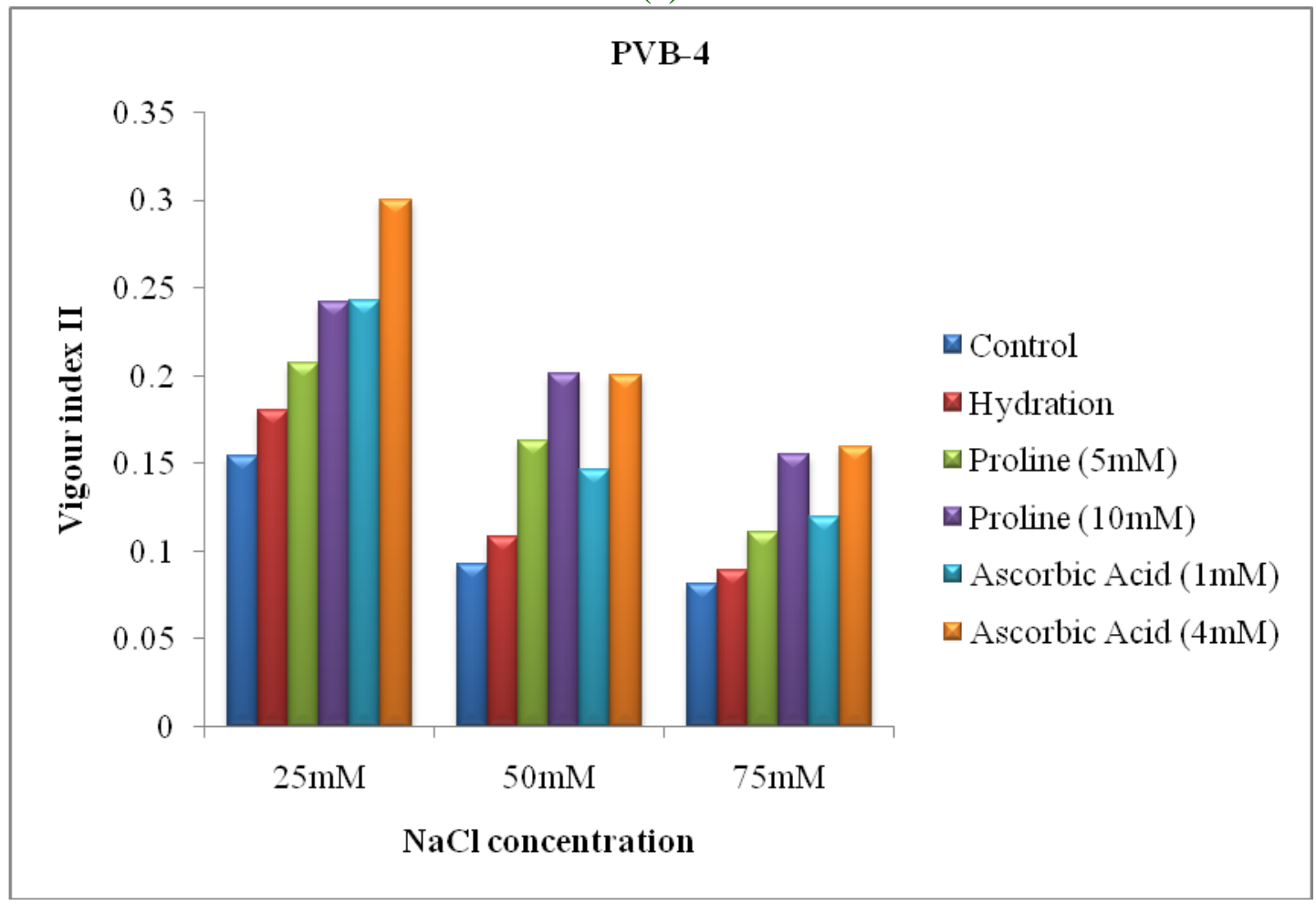

(b)

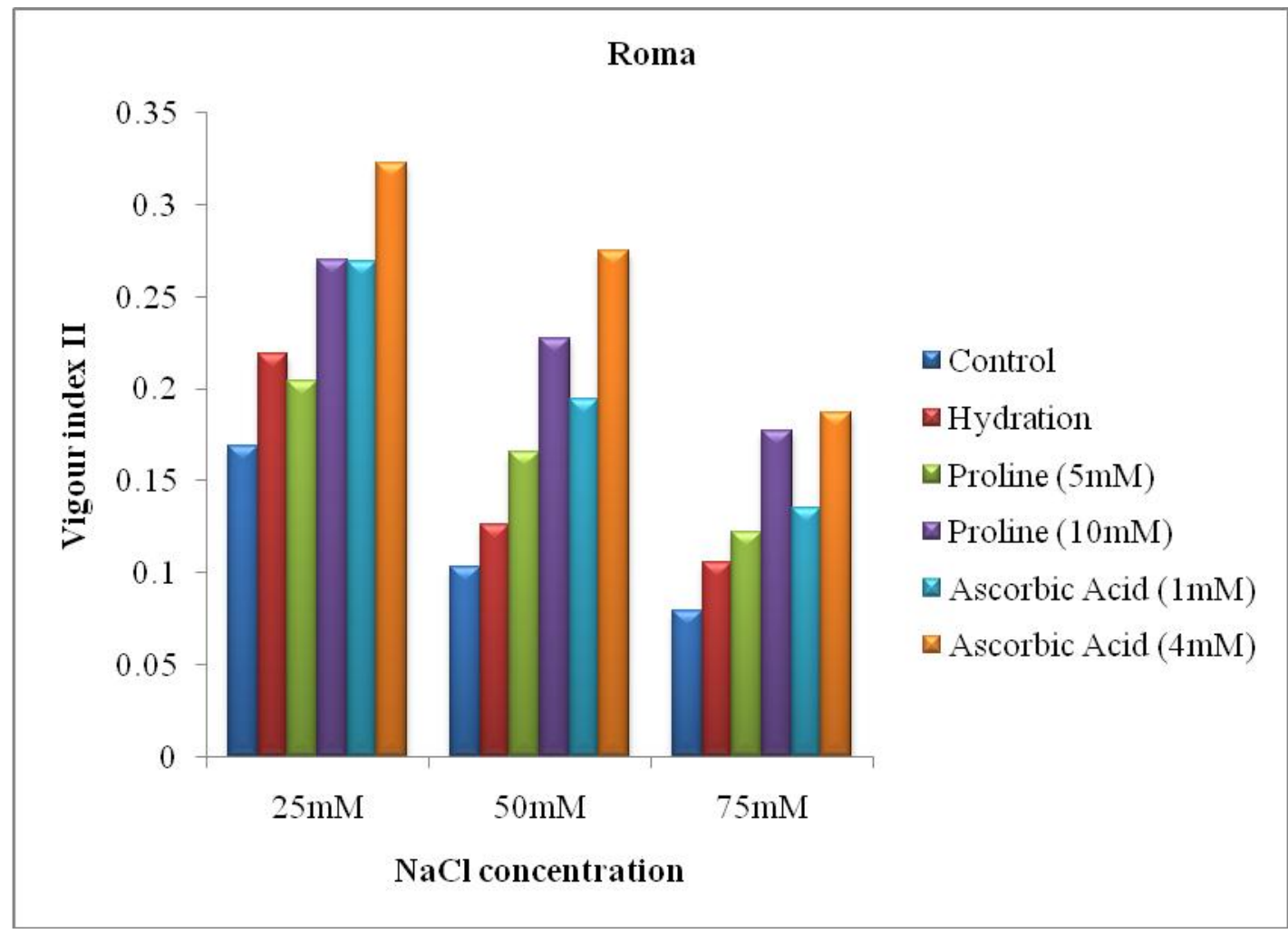


In same way, seedling vigour and seedling biomass showed inverse relationship with salt concentrations. Both the concentrations of proline and ascorbic acid showed increased seedling fresh and dry weight. Proline $10 \mathrm{mM}$ and ascorbic acid $4 \mathrm{mM}$ showed prominent affect in seedling biomass during salt stress, as depicted in figure (3) and (4). Ismail (2014) reported that exogenously applied proline enhanced fresh and dry weight in wheat under salt stress. According to Clausen (2014), proline helps in increasing fresh weight in tomato under abiotic stress conditions.

Seed vigour is the sum total of those properties of seed which determine the level of activity and performance of seed during germination and seedling emergence. Vigour index declines with increasing salinity levels.

In present study, both the concentrations of proline and ascorbic acid increased the vigour index I and II over control in PVB-4 and Roma at all salinity levels. But the affect of Proline $10 \mathrm{mM}$ and ascorbic acid $4 \mathrm{mM}$ was more as compared to proline $5 \mathrm{mM}$ and ascorbic acid $1 \mathrm{mM}$ respectively as showed in figure (5) and (6).

Vigour index of seedling in maize was also significantly affected under different salt stresses (Janmohammadi et al., 2008). Chemicals like proline and ascorbic acid accelerates the metabolism occurring in treated seeds that leads to increase vigour index in sorghum seeds (Guan et al., 2014).

Hence, pre-seed treatments with ascorbic acid $(4 \mathrm{mM})$ and proline $(10 \mathrm{mM})$ can be used to mitigate the adverse effect of salt stress in tomato seeds.

\section{References}

Akram, N. A., Shafiq, F. and Ashraf, M. 2017. Ascorbic Acid-A Potential Oxidant Scavenger and Its Role in Plant
Development and Abiotic Stress Tolerance. Front. Plant Sci., 8:613.

Billah, M., Rohman, M.M., Hossain, N. and Shalim, U. M. 2017. Exogenous ascorbic acid improved tolerance in maize (Zea mays L.) by increasing antioxidant activity under salinity stress. Afr. J. Agric. Res., 12: 1437-1446.

Clausen, R. G., Erturk, N. and Heath, L. S. 2014. Role of superoxide dismutase (SODs) in controlling oxidative stress in plants. $J$. Exp. Bot., 53: 1331-1341.

Ekmekci, B. A. and Karaman, M. 2012. Exogenous ascorbic acid increases resistance to salt of Silybum marianum L. Afr. J. Biotechnol., 11: 9932-9940.

Farooq, M., Aziz, T., Rehman, H. and Cheema, M. A. 2011. Evaluating surface drying and re-drying for wheat seed priming with polyamines: effects on emergence, early seedling growth and starch metabolism. Acta. Physiol. Planta. 33: 1707-1713.

Guan, B., Cao, D. and Yu, J. B. 2014. Ecophysiological responses of seed germination of sweet sorghum to seed priming. J. Eco., 33: 982-988.

Hemalatha, G., Renugadevi, J. and Evera, T. 2017. Studies on seed priming with hydrogen peroxide for mitigating salt stress in rice. Int. J. Curr. Microbiol. App. Sci., 6(6): 691-695.

Ismail, M. A. 2014. Exogenous proline induce changes in SDS-PAGE protein profile for salt tolerance in wheat (Triticum aestivum L.) seedlings. Res. J. Pharma. Biol. Chem. Sci. 5: 748-752.

ISTA. 2011. International rules for seed testing. International Seed Testing Association, Bassersdorf, Switzerland.

Janmohammadi, M., Moradi, Dezfuli, P. and Sharifzadeh, F. 2008. Seed invigoration techniques to improve germination and early growth of inbred line of maize under salinity and drought stress. Gen. Appl. Plant. Physiol., 34: 215-226.

Kaur, H. and Gupta N 2015. Exogenous application of salicylic acid and proline increase antioxidant enzyme activities at low temperature in cucumber (Cucumis sativus L.) Jour. Pl. Sci. Res.,31(2): 217223. 
Khan, T. A., Mazid, M. and Mohammad, F. 2011. A review of ascorbic acid potentialities against oxidative stress induced in plants. $J$. Agrobiol., 28: 97-111.

Manaa, A., Ahmed, H. B., Valot, B., Bouchet, J. P., Aschi-Smiti, S., Causse, M. and Faurobert, M. 2011. Salt and genotype impact on plant physiology and root proteome variations in tomato. J. Exp. Bot., 62: 2797-2813.

Mansour, M. M. F. and Ali, F.,E. 2017. Evaluation of proline functions in saline conditions. Phytochem., 140: 52-68.

Nahar, K., Hasanuzzaman, M., Fujita, M., 2016. Roles of osmolytes in plant adaptation to drought and salinity. In: Osmolytes and Plants Acclimation to Changing Environment: Emerging Omics Technologies (Eds.) Iqbal, N., Nazar, R., Khan, N. Springer Publishers, India. Pp 3768.

Nawaz, K., Talat, A., Iqra, M., Hussain, K., Majeed, A., 2010. Induction of salt tolerance in two cultivars of sorghum (Sorghum bicolor L.) by exogenous application of proline at seedling stage. World Appl. Sci. J. 10: 93-99.

Palop, S., Ozdikicierler, O., Kostekli, M., Escriva, M., Esteve, M. J. and Frigola, A. 2010. Ascorbic acid in tomatoes during refrigeration storage with absorbing sheet of ethylene. Inter. Conf. Food Innov, 1-4.

Rafique, N., Raza, S. H., Qasim, M. and Iqbal, N. 2011. Pre-sowing application of ascorbic acid and salicylic acid to seed of pumpkin and seedling response to salt. Pak. J. Bot., 43: 2677-2682.

Sajid, Z. A. and Aftab, F. 2009. Amelioration of salinity tolerance in Solanum tuberosum L. by exogenous application of ascorbic acid.
In. vitro. Cell. Dev. Biol. Plant.,45: 540549.

Sayed, El., Hameda, E. A., Baziad, Salih, A. M., Basaba and Reem, A. A. S. 2016. Alleviated effect of salinity stress by exogenous application of ascorbic acid on the antioxidant catalase enzymes and inorganic mineral nutrient elements contents on tomato plant. Int. J. Life. Sci. 4: 467-490.

Shalata, A., Mittova, V., Volokita, M., Guy, M. and Tal, M. 2001. Response of the cultivated tomato and its wild salt-tolerant relative Lycopersicon pennellii to saltdependant oxidative stress: the root antioxidative system. Physiol. Plant. 112: 487-494.

Shruti and Gupta N 2015. Effect of salicylic acid and proline on seed germination and antioxidant enzymes in aged seeds of radish (Raphanus sativus L.) Jour. Pl. Sci. Res.,31(1): 91-96.

Singh, J., Divakar, Sastry, E. V. and Singh, V. 2012. Effect of salinity on tomato (Lycopersicon esculentum Mill.) during seed germination stage. Physiol. Mol. Biol. Plants. 18: 45-50.

Talat, A., Nawaz, K., Hussian, K., Bhatti, H. K., Siddqi, H. E., Khalid, A., Anwer, S. and Sharif, U. 2013. Foliar application of proline for salt tolerance of two wheat (Triticum aestivum L.) cultivars. J. World. Appl. Sci. 22: 547-554.

Zhang, P., Senge, M. and Dai, Y. 2017. Effect of salinity stress at different growth stages on tomato growth, yield and water use efficiency. Rev. Agric. Sci. 48: 624-634.

\section{How to cite this article:}

Kaur, H. and Gupta, N. 2018. Ameliorative Effect of Proline and Ascorbic Acid on Seed Germination and Vigour Parameters of Tomato (Solanum lycopersicum L.) Under Salt Stress. Int.J.Curr.Microbiol.App.Sci. 7(1): 3523-3532. doi: https://doi.org/10.20546/ijcmas.2018.701.414 